\title{
INTERPRETATIONS OF DESIGN THINKING ACROSS A LARGE ORGANIZATION
}

\author{
Kosmala, Martyna; van der Marel, Floris; Björklund, Tua \\ Aalto University
}

\begin{abstract}
Design thinking has a prominent role as established corporations ramp up innovation efforts focusing on user needs. Current literature provides a plethora of definitions for design thinking with variations in tools, methods and cultures. This study aims to identify differences in perception and maturity of design thinking across different contexts within a large corporation. The results are based on a thematic analysis of nine semi-structured interviews with industrial and user experience designers in the case company, operating in different countries and three different organizational contexts: lone designers of a region, unit-embedded design team managers and global-level design managers. The results echo the literature in finding no uniform definition of design thinking. Instead, it was seen as a continuous scale of practices, cognitive approaches and mindsets aiming for stronger user-centrism in the organization. Practices and maturity varied between contexts, indicating that to strengthen the role of design in an organization, a deep understanding of the context is crucial for a successful implementation.
\end{abstract}

Keywords: Design practice, Design management, Organizational processes, Design maturity

\section{Contact:}

van der Marel, Floris

Aalto University

Mechnical Engineering, Design Factory

Finland

floris.vandermarel@aalto.fi

Cite this article: Kosmala, M., van der Marel, F., Björklund, T. (2019) 'Interpretations of Design Thinking Across a Large Organization', in Proceedings of the 22nd International Conference on Engineering Design (ICED19), Delft, The Netherlands, 5-8 August 2019. DOI:10.1017/dsi.2019.400 


\section{INTRODUCTION}

Many studies have shown that organizations often perform better when adopting design thinking (e.g. Rae, 2016). However, its ambiguous nature often conflicts with established organizational processes and non-adaptive cultural pressure (Walters, 2011). Furthermore, multinational corporations often grapple with communication and reporting challenges as its interpretation is heavily dependent on the contextual situation and its conditions (Brereton \& McGarry, 2000). At these large organizations, especially where many formalized processes and wide varieties of working habits exist, pushing employees out of their usual working patterns by introducing iterations and experimentation proves to be a challenge as these organizations rarely support employees with psychological safety to take risks and experiment (Liedtka et al., 2017). Additionally, designers generally have a weak understanding of managerial activities (Mozota, 2010), making it hard to develop business key performance indicators for design (Rauth, Carlgren, \& Elmquist, 2014) and fit innovative project outcomes to organizational boundaries and predefined objectives (Dunne \& Martin, 2006).

Current literature represents a multitude of perspectives on design thinking, although all hold usercentricity at their core and highlight design practice, skills or attitudes. For example, Gruber et al. (2015) describe design thinking mainly as an attitude, "a human-centered approach to innovation that puts observation and discovery of often highly nuanced, even tacit human needs right at the forefront of the innovation process". Kolko (2015), drawing on Clark and Smith (2010), highlights practices, describing design thinking as a tool for simplifying and humanizing complex problems by focusing on user experiences and emotions, while simultaneously leveraging emotional, integral and experimental intelligence. Liedtka (2011) states design thinking is best understood as a skillset, such as the ability to handle uncertainty, tolerate ambiguity and maintain the big picture through systems thinking and system design. For management discourse, Hassi and Laakso (2011) conclude varying definitions into a three-dimensional framework which suggests that implementing design thinking in organizational processes requires a combination of practices, cognitive approaches and mindsets.

Several best practices describe the integration of design thinking into operational and strategic organizational processes. To implement design thinking in regular projects, most possess similar underlying logic (Liedtka et al., 2017), often the widely known model developed by Stanford University's d.school (d.school, 2018), describing five iterative steps: 1) empathizing with users, 2) defining the challenge, 3) ideating possibilities, 4) prototyping and 5) testing. To integrate designerly ways of thinking and working into the strategic level of an organization, Bucolo et al. (2012) explain how organizations can develop design efforts by demonstrating design thinking resources across various contexts and projects by iteratively identifying hidden needs of users, converting them into future oriented solutions and adjusting the company's strategy continuously.

As large organizations go through the process of changing, the internalization of design thinking across business units might vary wildly, from managerial direction to hands-on activities. Some frameworks developed to assess design maturity in organizations focus on defining the role of design in the organization, e.g. Design Ladder (Danish Design Centre, 2001) and DMI Design Value Scorecard (Westcott et al., 2013), whereas others emphasize potential next steps to take (e.g. Girling, 2015; Mozota, 2010). For example, the Design Ladder describes a total of four possible design levels in organizations:

1. Level 1. Non-design: systematic way in which tasks are handled by non-designers and decisions are made based on own assumptions instead of user insights;

2. Level 2. Design as form-giving: finishing action in product development or graphic design, or 'styling', conducted by either designers or other professionals;

3. Level 3. Design as process: mindset of integrating design at an early stage of the development process driving the solution based on user input and identified challenges;

4. Level 4. Design as strategy - close collaboration between designers and the management team aiming to rethink business concepts and value chains.

While the Design Ladder defines the maturity of design on an operational level, Doherty et al. (2014) add a strategic perspective and propose three "cultural stepping stones" applied between the second and third step of the ladder. The stepping stones describe the shift of the role of design from productfocus to design integration on strategic level:

1. Stone 1. Design as Thinking: design as a unique tool for approaching and solving problems

2. Stone 2. Design as Value Creation: design as a method to create value for stakeholders, shortterm outputs and long-term outcomes 
3. Stone 3. Design as Intangible: allows for uncertainty and accepts that outcomes can be intangible. As Carlgren et al. (2016a) suggested, the rising of design thinking in organizational culture is vastly different from previous paradigm shifts in this domain, thus rendering previously learned obstacles to change irrelevant. This study investigates whether the term of and experiences with design thinking are perceived differently by designers representing varying work contexts within one organization. In these contexts, designers perform active and hands-on roles to internalize designerly way of working across the organization. The results aim to contribute to understanding how to better support design thinking implementation efforts in large and well-established organizations.

\section{METHODOLOGY}

The study aimed to understand different perceptions of design thinking in a large organization, to shed light on contextual struggles designers face when advancing design in their organization. The participating organization is a Fortune 500 multinational and industrial corporation providing their B2Bcustomers with physical products, software and complementary services. The company operates in around 100 countries and employs more than 100,000 employees around the world. 37 designers participated, of which nine were selected for analysis in the current study based on their role in the organization and working location. All nine were industrial or user experience (UX) designers, representing three different work contexts within the organization: 1) lone UX designers in the region working for one business unit; 2) business unit-embedded design team managers and 3) global-level design managers working for more than one business unit. They were working in four different regions: Australasia $(n=1)$, Central Europe $(n=2)$, Northern Europe $(n=4)$, and North America $(n=2)$. Their average tenure in the company was 5.5 years, ranging from 0.5 to 12 . All three work contexts had designers from at least two different regions.

Semi-structured qualitative interviews were conducted asking open-ended questions on organizational culture, design practices, as well as inquiring about positive and negative experiences at the company to explore views, experiences, beliefs and motivations of individual designers on a research topic while simultaneously giving flexibility to discover new perspectives (Gill et al., 2008). Interviews were conducted face-to-face or via video conference, ranging from 29 to 69 minutes, with an average of 53 minutes. They were audio-recorded and transcribed verbatim.

The various perceptions of design thinking were first coded top-down and analyzed bottom-up to identify similar themes (Braun \& Clarke, 2006). The coding framework followed four themes identified by Carlgren et al. (2016b) in their exploratory study with 31 individuals working with design thinking in 16 companies to identify roles and impact of design thinking in large organizations. The third theme was modified to reflect not only implications in product development but in all organizational processes.

- Theme 1. Perception of the term design thinking - designer's personal understanding of the term

- Theme 2. Use of design thinking - how design thinking is utilized and what kind of tools and techniques are used

- Theme 3. Implication of design thinking for organizational processes - how design thinking is connected to companies' product development processes

- Theme 4. Who uses design thinking - who in the company is using the design thinking method as well as the role of professional designers in relation to design thinking

After coding the interview with the four themes, excerpts were analyzed and coded thematically per interview to gain deeper understanding of the role of design for the individual interviewee. Then, individual findings were summarized into characteristics for each of three work contexts. The three contexts were compared to each other to highlight differences and similarities between them and explore whether the results suggested any further implications for the role of design in the company.

\section{RESULTS}

In total, the participants mentioned 49 activities of design thinking (Theme 2) and 59 examples of its implications in organizational processes (Theme 3). Each of the three work contexts was represented by three designers (total $n=9$ ). The higher the designers' position in the organizational structure, the more activities and its implications for organizational processes they described from their daily work. Lone designers (Context 1) shared 12 activities and 11 implications, when unit-embedded design team leads mentioned 15 activities and 20 implications. Finally, global-level design managers, with the higher 
impact in organizational structure recognized 22 activities with 28 implications for organizational processes. Table 1 lists insights per work context.

Table 1. The perception of design thinking in three work contexts

\begin{tabular}{|l|l|}
$\begin{array}{l}\text { Context 1 - Lone UX } \\
\text { designer in the region }\end{array}$ & $\begin{array}{l}\text { Context 2 - Unit-embedded } \\
\text { design team lead }\end{array}$ \\
\hline \begin{tabular}{l|l} 
1. Perception of the term design thinking \\
A way to make people's
\end{tabular} & $\begin{array}{l}\text { A method of taking user needs } \\
\text { lives better (these designers }\end{array}$ \\
$\begin{array}{l}\text { into consideration } \\
\text { sharing their understanding) }\end{array}$ & \\
\hline 2. Use of design thinking within organization \\
\hline - Conducting user testing & - Creating experiences for \\
but in "improper" way & users (3) e.g. both physical and \\
(remotely, internally or with & digital; user groups based on \\
limited access to users) (3) & their products utilized \\
- Simplifying products - & - Establishing continuous \\
combining and throwing & feedback loop with users (2) \\
features out (2) & - Identifying opportunities (2) \\
- Defining personas (2) & - Focusing on exact users' \\
- Conducting workshops & needs (e.g. customizing) (2) \\
with clients e.g. at user & - Conducting user research (2) \\
conferences to test and & - Defining role of designers as \\
interact (2) & organizational glue - multi- \\
- Visiting users but only & sided collaboration (1) \\
sporadically (2) & - Defining global design \\
- Using user data to support & guidelines (1) \\
decisions (1) & - Communicating and internal \\
& selling through proposals and \\
& prototypes (1) \\
\hline & - Educating how to focus on \\
users (1)
\end{tabular}

\section{Design thinking in relation to product development efforts}

- Not enough know-how to implement UX design ("half doing", focus on UI) (4) - Developer-centric culture with agile methods by the book (3)

- Lacking user-centricity, no expectations for design inside organization (2) - Improving workflows and including designers from the beginning of the project (2)
- Improving products based on clients' feedback e.g. open house, workshops with clients (4)

- Communicating design visually and simply; educating others (4)

- Involving and budgeting design on daily basis from the beginning of the project (3)

- Focusing holistically on humans and their real needs (3) - Coping with highly technology-driven culture (2) - Mixing backgrounds around organization, also hard and soft skills (2)

- Conducting ad hoc testing with people using the products (1)

- Defining future vision and strategy for products (1)
Context 3 - Global-level design manager

A mindset of always involving users when possible, keeping the "big picture" in mind

- Ideating with users from the beginning and creating feedback loop (4)

- Thinking system, concentrating on big picture (4)

- Implementing agile (3)

- Acting as "body of knowledge"

(3)

- Including DT in concrete ways

e.g. checklists (2)

- Conducting workshops with

different units (2)

- Connecting people for

collaboration and knowledge

sharing (2)

- Creating culture of openness (1)

- Prototyping (1)

- Acting as supporting services for BUs and projects (consultancy or guidelines and principles) (6)

- Breaking silos and boosting knowledge sharing

(workshops/education) (5)

- Gathering user insights on the spot and from the beginning of processes (4)

- Creating open culture of trust, e.g. retrospectives, open office (4)

- Being lean and agile - fast prototyping, minimum valuable product (3)

- Experimenting to reduce risks

- Aiming high, creating a strong connection towards products (2)

- Promoting design with organizational design and empirical shows of user-centrism benefits (2) 
4. Who uses design thinking

\begin{tabular}{l|l|l|}
$\begin{array}{l}\text { - Mainly alone, some } \\
\text { collaboration with other } \\
\text { parts of organization }\end{array}$ & - Teams & $\begin{array}{l}\text { - Not specified who uses design } \\
\text { thinking, perceived as relevant for } \\
\text { all organizational actors }\end{array}$ \\
\hline
\end{tabular}

\subsection{Context 1 - UX designer working alone}

The lone UX designers in their region (interviewees 1, 2 and 3) indicated not being completely familiar with the term design thinking. However, when prompted, two of these designers associated it with "making a user's life better" or with general improvements to the company's existing solutions. While hesitant to offer a definition, one of these designers took design thinking as a "culture of design" and as a method to show differences between easy and difficult interfaces.

"I would say I'm not familiar enough with it, to be honest. (...) To me, design is about making a user's life better. That's the term I'd like to use, that's my whole focus. My focus is 'Are we doing something that actually makes their life easier?' 'Are we doing something that makes their life harder?', 'What are we doing?'. And often we don't know the answer. We have no idea what the answer is. And that's, to me, been my main focus. And that's how I sell it to others. And they sort of... it's hard to argue with that statement." (interviewee 1)

The third designer in this context also highlighted the resulting designs, with a strong focus on visuals creating a "wow-factor" and making products "not only work well but also look good".

The lone designers mentioned a total of 12 design thinking activities. High level examples included activities aimed at making existing solutions more simple and user-friendly by, for example, gathering data of users in situ or by cutting unnecessary product features. Most examples of user interaction were somehow related to testing existing solutions sporadically with customers or other co-workers to verify user needs. As exemplified below, the designer was working on future ideas how to improve complicated existing products to more user-approachable ones, however, without continuous interaction with users.

"And I'm also working on future ideas, one is breaking up the system, it's a very complicated application and we are breaking it up into workflows, very specific roles/ personas, they call it personas, but we are not really working as personas, as we know, UX designers know it, but it's more of a role specific. So, I'm doing research, unfortunately not with user, with just people inside the company who know this works. So, this is just the beginning and we are gonna present it to users in conference in April. So, I'll be able to interact with users at this point. And we'll test some of our current features, mobile apps and also present this new concept then." (interviewee 3)

Furthermore, lone designers mentioned 11 examples of design thinking implications for organizational processes. All designers aimed to incorporate a better user experience in both new and existing products. They put effort in implementing design thinking activities in existing organizational workflows and spreading the world of UX resources among non-designers who didn't have expectations for design yet. However, they described their efforts as "half-doing" since the organization lacks knowledge and resources to conduct changes fully and strengthen the role of design thinking in existing workflows. More precisely, they conducted testing but only remotely with limited and coincidental access to users or in-house only with access to people developing products, with the focus on UI instead of UX. One of the designers in this context brought up budget and resource constraints to implement design thinking as the organization considered it not to be the cheapest or easiest way of working. In general, the developing culture was seen as a very developer-centric, following agile principles by the book. There were mixed opinions whether agile helped designers to strengthen the role of design thinking or not. As exemplified below, one of the designers reported general lack of knowledge and skills on implementing UX design, as well as lack of prioritization among other tasks in agile teams, while another praised designers' easy involvement in the project team from start to finish, although mainly focusing on visuals.

"It's kind of sad because I feel like they don't really set expectations. The expectations are so low

- for design. And they say that they want the design, but a lot of times my design will end up being brushed off until a later time or put on hold." (interviewee 2)

All designers in this context conducted their work mainly alone rarely collaborating with product owners or developers. In one business unit, a designer worked alone on five products, despite belonging to a remote team three other designers. Another designer who also worked alone received support sporadically from sales people, product owners and managers. The third designer worked alone without any collaboration on product designs but for big strategic decisions for the product, project managers or 
product owners were consulted. This designer also tried to strengthen bonds with designers located in other regions working in the same organization.

\subsection{Context 2 - Unit-embedded design team leads}

All three unit-embedded design team leads (interviewees 4, 5 and 6) associated design thinking with user involvement, for example combining physical and digital user experiences to suit user needs. Additionally, one designer described design thinking as a good method for non-designers to understand the purpose of user-centered design and its iterative way of gathering users' inputs.

In total, unit-embedded design team managers mentioned 15 design thinking activities. From an organizational perspective, designers used design thinking to change processes and combined activities to improve the user experience, such as better identification of needs and approaching user interaction more holistically. For example, one design team sent their users test products, gathered insights from the feedback, revealing architectural mistakes created long ago.

"We just gathered some people very ad hoc that are working with the machine to test and get some feedback. We conducted tests and then got a list what could be improved. It was kind of an eye opener what should have been done already one and half years ago. We revealed some architectural mistakes, which were expensive to repair now, and there was not even time for them. It was something that helped us to show what should have been done a while ago." (interviewee 4)

Unit-embedded design team leads provided 20 examples of how design thinking activities are put into practice within organizational processes. Though the culture was seen as technology-driven, designers reported examples of how products or processes were improved based on users' feedback. They also highlighted efforts to involve other organization and non-designers to design thinking activities, as exemplified below, through education, simple communication and multidisciplinary teams.

"I think that we are more about the client or user or human as center of approach than design thinking itself, so we are showing them that, I mean, from my perspective, it's much more value over, for developers, that you are showing, that the things which they developed make sense and they will be useful for the users, and it's as simple as that and they understand that. So, we are not really teaching them about the design, because it's our part, sometimes of course if they want to know something, we're telling them what we know, but we are showing them that what they are doing and why they are working with us, is important. And why we are going to the client or why we are asking the client what they think about our mock-ups and why they, their feedback is important." (interviewee 5)

"And that's what I'm trying to mix up, I have not an engineer background, from Umeå Institute of Design, and it's in fine arts, and then I have one from the cognitive science, also in my team, and I want to mix up that more, and I have one with business background and design on top of that. So that is something that I'm trying to mix up more, but it is a very engineering-heavy company, so working with these softer values, they have a little bit difficulty sometimes to see why they should do that because that is still quite new." (interviewee 6)

To strengthen the role of design in organizational processes, they emphasized the importance of involving and budgeting design from the start of the project. Additionally, designers developed global design guidelines, defined future visions and product strategies and communicated design in a simple and understandable way.

Unit-embedded design team managers collaborated with other organizational parts, such as product managers, developers or product owners weekly. For example, designers explained how their team of six designers worked closely with business units and participated regularly in Scrum meetings, and how they combined user research efforts of industrial and service designers.

\subsection{Context 3 - Design managers working on global level}

The global level design managers (interviewees 7, 8 and 9) occupied the highest design position in the organization, although still relatively low in the overall hierarchy of the company. They associated design thinking with a mindset of involving users as early as possible while keeping a bigger picture in mind. More precisely, one designer described design thinking as a development starting from a bigger perspective, developing new radical ideas, collaborating with the real users, testing concepts, experimenting without getting stuck on initial solutions, as well as involving people with different backgrounds. As exemplified below, some designers decided to take advantage of the cultural diversity of its employees around the world. 
"We tested our concept by travelling all over the world and gathering our internal insights from engineers and project-engineers located in Singapore, China, USA, England, Sweden and Norway" (interviewee 7)

Another designer perceived design thinking to be a human-centered, co-creation approach allowing people to solve their own problems.

"For me, it means... well, it's a co-creation with users, I would boil it down to just one sentence. People have natural capability to solve their own problems, if they are given freedom, space and responsibility. So, I think (with) design thinking, want to nurture exactly it. So, we want to invite users to help them solve the problems, and then, just work together to pack it and wrap that up into a good solution." (interviewee 8)

The third designer in this context described design thinking as a lean and agile method focused on understanding users to develop easy and usable user interfaces.

These designers mentioned 22 examples of design thinking activities, most frequently highlighting the iterative and holistic involvement of users for ideation and feedback. Understanding the "domain" and "big picture" was seen as a crucial enhancer in successful product development and risk mitigation. One designer highlighted the importance of UX design and systems thinking:

"Those products need to work together when we build those kinds of process industry solutions, we connect different products and make a system. However, UX design is included now only through 'bottom-up' work of designers - we need some more higher support to get it on next level and create competitive advantage out of it." (interviewee 9)

Designers also encouraged incorporating agile ways of working to include users' perspectives, such as frequent releases of prototypes and minimum valuable products (MVP). They were acting as a "body of knowledge" connecting people to collaborate with each other.

Global-level design managers mentioned 28 examples of design thinking integrated into organizational processes. They enforced design as a support service for various business units and projects. The aim was not only to improve products with user feedback, prototyping and MVPs, but also to break silos and connect people with each other combining their expertise and boosting knowledge sharing. Design was promoted by showing the value of user-centrism and doing workshops with different units. The activities used included research, conceptualization and prototyping in agile working practices. One designer highlighted the importance of culture of design including open communication, trust and transparency, experimentation, aiming high, as well as creating strong connection between employees and their work, as visible below, to encourage responding to the problems as they emerge.

"Because, again, we strongly believe that if people love the products, they work hard, the products will be good. It's like with food. Unless you love food and treat it with love, you can't cook tasty dishes." (interviewee 8)

Designers working on the global-level only specified stakeholders involved in design thinking activities on a general level, such as the IT, R\&D departments, or digital leads.

\subsection{Comparison of work contexts}

In comparison, lone UX designers mostly worked on solving current drawbacks in products by implementing practices of design thinking, design teams worked to change parts of the company's development processes, and global-level managers focused on influencing the organizational culture even across business units. Table 2 provides a summary of the identified differences in perceptions and implications of design thinking per context.

Table 2. The summary of three work contexts

\begin{tabular}{|l|l|l|}
\hline $\begin{array}{l}\text { Context } 1 \text { - UX designer } \\
\text { alone }\end{array}$ & Context 2 - Design team & $\begin{array}{l}\text { Context 3 - Group level } \\
\text { manager }\end{array}$ \\
\hline $\begin{array}{l}\text { 1. Perception of the term design thinking } \\
\begin{array}{l}\text { Associated with good design } \\
\text { practices (however, not very } \\
\text { comfortable with the term) }\end{array}\end{array}$ & $\begin{array}{l}\text { Involving user needs } \\
\text { sporadically }\end{array}$ & $\begin{array}{l}\text { Mindset of involving users } \\
\text { always when possible, keeping } \\
\text { "big picture" in mind }\end{array}$ \\
\hline
\end{tabular}




\begin{tabular}{|c|c|c|}
\hline \multicolumn{3}{|l|}{ 2. Use of design thinking } \\
\hline $\begin{array}{l}\text { Concrete and individual } \\
\text { actions within the process } \\
\text { (12 activities described) }\end{array}$ & $\begin{array}{l}\text { Continuous and holistic } \\
\text { approach to drive the bigger } \\
\text { parts of development processes } \\
\text { (15 activities described) }\end{array}$ & $\begin{array}{l}\text { Driving the whole development } \\
\text { process, connecting different } \\
\text { processes ( } 22 \text { activities described) }\end{array}$ \\
\hline \multicolumn{3}{|c|}{ 3. Implication of design thinking in organizational processes } \\
\hline $\begin{array}{l}\text { Facing and solving } \\
\text { challenges (11 implications } \\
\text { described) }\end{array}$ & $\begin{array}{l}\text { Actionable and continuous } \\
\text { change efforts ( } 20 \text { implications } \\
\text { described) }\end{array}$ & $\begin{array}{l}\text { Cultural change, and breaking } \\
\text { existing structures ( } 28 \\
\text { implications described) }\end{array}$ \\
\hline \multicolumn{3}{|c|}{ 4. Who uses design thinking } \\
\hline $\begin{array}{l}\text { Working alone in the } \\
\text { region or one organization } \\
\text { (e.g. business unit) }\end{array}$ & $\begin{array}{l}\text { Team of designers working in } \\
\text { one organization (e.g. business } \\
\text { unit), some external } \\
\text { collaboration }\end{array}$ & $\begin{array}{l}\text { Not specified, rather referring to } \\
\text { entire functions, occupational } \\
\text { groups and units, such as IT or } \\
\text { product owners }\end{array}$ \\
\hline
\end{tabular}

To recap, levels of abstraction in defining design thinking varied significantly. Lone UX designers were not completely comfortable with describing the term design thinking but highlighted mostly concrete, individual practices, such as testing, simplifying or creating personas. However, since the organization did not have high expectations regarding design, the work was described as "half-doing". Through individual practices they managed to improve drawbacks in current products and one-on-one interactions. When designers were working with the team, however, they involved users more to change bigger parts of product development process. They concentrated on creating experiences for users by involving them continuously, focusing on real needs, and identifying opportunities. Finally, global-level designers associated design thinking with organizational culture in which opinions of users and the "big picture" are at the forefront. Design thinking activities were present in the entire development process, connected different workflows, aiming at changing the company culture and breaking silos.

\section{DIscussion}

Within the same organization, various descriptions were connected to design thinking depending on the hierarchical position of the designer. Interviewees' varying responses, when describing their own perception of design thinking, are in line with a statement from previous literature that there is no single and unified definition of design thinking. Designers working alone in a region were not completely comfortable with the term but highlighted mostly personal attempts of applying individual practices of design thinking. Lone designers' efforts seemed to reflect Baker and Nelson's (2005) theory of bricolage: needing to scrappily combine available resources to push for change. Designers leading unit-embedded design teams perceived design thinking as "incorporating user needs", manifesting in concrete actions focused on the development process, such as continuous feedback loops, adapting products to needs, and creating a better user experience. Designers leading global teams and working with several business units saw design thinking as a new mindset, as they emphasized promoting experimentation, creating an open culture of trust, setting high and visionary goals, involving users when possible, and keeping the "big picture" in mind. For them, design thinking was a tool to enhance both the development process and connect siloed parts of the organization by boosting knowledge sharing. To summarize, lone designers focused on personal attempts, unit-embedded design team leads on the entire development process, and global-level designers on organizational culture as a whole, echoing previous literature on the multifaceted nature and varying definitions of design thinking (Hassi \& Laakso, 2011).

The results confirm that besides understanding of design thinking, also the maturity of design can vary widely even within a single organization. The lone designers complained about scarce access to users when it comes to decision-making, typical for non-design organizations, Step 1 of the Danish Design Ladder (Danish Design Centre, 2001). Lone designers also stated there is more focus on UI than on UX, and limited involvement of designers in the development process, indicating design was mostly used as finishing touches in product development or graphic design, Danish Design Ladder's Step 2. For example, one designer described encountering products with little design:

"The current project they work on it's a [application]. And it's never had a UX Designer and you can see that because it's just really funky, I would say, the workflows are very laborious. Lots of clicks and clicking back and forth between displays. [...] So, it's, it needs UX design, and they [the software teams] know that but they just don't quite know how to implement UX design with their process." 
Designers working in unit-embedded design teams, however, utilized design as an integrated element in the development process (Step 3). Activities identified in the unit-embedded design team, such as experience creation, show that design thinking is perceived not just as a tool for problem solving but as a way to create value for short-term and long-term stakeholders, implying that the design teams were on the second Cultural Stepping Stone (Doherty et al., 2014). As one of the team leads remarked:

"We work close with the business, we also work close to the team, because we're showing them what has to be done, and also, we are working closely with the client and it should be always like that because we need to evaluate our ideas, and the only possibility to do that is by a workshop or meetings or research with the client."

Finally, global-level designers' experiences pointed to using design as strategy (Step 4), however no definitive examples were given indicating design's key strategic role in the business model. Their stories described more Step 3 type of activities, but with successful implementation of all three Cultural Stepping Stones. As one of the design managers described her role:

"I would say that my job is more to do organizational design [...], I design the culture, the mindset. I talk a lot and I promote a lot. I try to push design to every possible situation, and simultaneously I try to listen what they do in different place organization. Then, I try to get right people to right places."

Based on the results, design thinking can be understood as a continuous scale of activities (Table 3) strengthening design in the organization. Lone designers tried to uncover user needs and implement what they reported as design thinking activities in their own daily practice, such as conducting user research, prototyping or testing. Unit-embedded design teams established design-driven product development processes by stimulating cognitive approaches, such as collecting feedback, integrative thinking or a viewing problems more holistically. Global-level designers highlighted connecting design thinking to organizational culture, thus, coming up with design principles so that it becomes a natural way of thinking and doing. In the current study, perhaps due to the relatively low position in the company's managerial level of even the global-level design managers, no examples were given of using design thinking to define or adjust the company strategy (Step 4 of the Danish Design Ladder).

Table 3. Continuous scale of perceptions of design thinking

\begin{tabular}{|l|c|c|c|}
\hline & \multicolumn{2}{|c|}{ Global-level design managers } \\
\hline & Lone Designers & \\
\hline $\begin{array}{l}\text { Three-dimensional } \\
\text { design thinking- } \\
\text { definition for } \\
\text { management discourse } \\
\text { (Hassi \& Laakso, 2011) }\end{array}$ & Practices & Cognitive Approach & Mindset \\
\hline $\begin{array}{l}\text { Putting design thinking } \\
\text { to practice (d.school, } \\
\text { 2018) }\end{array}$ & $\begin{array}{c}\text { Utilizing the } \\
\text { practices of the } \\
\text { process }\end{array}$ & $\begin{array}{c}\text { Implementing the } \\
\text { process within } \\
\text { organizational } \\
\text { structure and its } \\
\text { processes }\end{array}$ & $\begin{array}{c}\text { Planting the process } \\
\text { into people's mindset } \\
\text { to drive their actions } \\
\text { accordingly }\end{array}$ \\
\hline $\begin{array}{l}\text { Design-led innovation } \\
\text { framework } \\
\text { (Bucolo } \text { et al., 2012) }\end{array}$ & $\begin{array}{c}\text { Understanding the } \\
\text { hidden needs of the } \\
\text { stakeholders }\end{array}$ & $\begin{array}{c}\text { Converting the insights } \\
\text { into future oriented } \\
\text { solutions }\end{array}$ & $\begin{array}{c}\text { Adjusting the strategy } \\
\text { and validating it with } \\
\text { users }\end{array}$ \\
\hline
\end{tabular}

\section{CONCLUSION}

More research is needed to extend the findings of this study to other contexts, however, the results of this study illustrate the differences and cluster patterns in understanding and practices of design thinking among varying work contexts, even within a single organization. The higher the designer is positioned within organization and the more designers around to collaborate with, the more design thinking is associated with the right mindset, as well as the more strategic purposes it is used for. This suggests that advancement efforts based on the maturity of an entire organization are a misleading foundation. Rather, successful and further advancing of design thinking into established organizational processes requires, first, investigation of differences in perception and practices of design thinking 
across various designers' working contexts even inside single organization, and then more nuanced tailored efforts for each specific context.

\section{REFERENCES}

Baker, T. and Nelson, R.E. (2005), "Creating Something from Nothing: Resource Construction through Entrepreneurial Bricolage", Administrative Science Quarterly, Vol. 50 No. 3, pp. 329-366. https://doi.org/10.2189/asqu.2005.50.3.329.

Braun, V. and Clarke, V. (2006), "Using thematic analysis in psychology", Qualitative Research in Psychology, Vol. 3 No. 2, pp. 77-101. http://dx.doi.org/10.1191/1478088706qp063oa.

Bucolo, S., Wrigley, C. and Matthews, J. (2012), "Gaps in Organizational Leadership: Linking Strategic and Operational Activities through Design-Led Propositions: Gaps in Organizational Leadership", Design Management Journal, Vol. 7 No. 1, pp. 18-28. https://doi.org/10.1111/j.1948-7177.2012.00030.x.

Carlgren, L., Elmquist, M. and Rauth, I. (2016a), "The Challenges of Using Design Thinking in Industry Experiences from Five Large Firms", Creativity and Innovation Management, Vol. 25 No. 3, pp. 344-362. https://doi.org/10.1111/caim.12176.

Carlgren, L., Elmqvist, M. and Rauth, I. (2016b), "Exploring the use of design thinking in large organizations: Towards a research agenda", Swedish Design Research Journal, Vol. 11 No. 1, pp. 55-63. http://dx.doi.org/10.3384/svid.2000-964X.14155.

Clark, K. and Smith, R. (2010), "Unleashing the Power of Design Thinking”, Design Management Review, Vol. 19 No. 3, pp. 8-15. https://doi.org/10.1111/j.1948-7169.2008.tb00123.x.

Danish Design Centre (2001), The Design Ladder, [online] Danish Design Center. Available at: https://danskdesigncenter.dk/en/design-ladder-four-steps-design-use (accessed 1.9.2018).

Doherty, R., Wrigley, C. and Matthews, J. (2014), "From Valuing Design to Designing Value", NordDesign, Vol. 2014.

d.school (2018), An Introduction to Design Thinking Process Guide. [online] d.school. Available at: https://dschoolold.stanford.edu/sandbox/groups/designresources/wiki/36873/attachments/74b3d/ModeGuid eBOOTCAMP2010L.pdf (accessed 1.9.2018).

Gill, P., Stewart, K., Treasure, E. and Chadwick, B. (2008), "Methods of data collection in qualitative research: interviews and focus groups", British Dental Journal, Vol. 204 No. 6, pp. 291-295.

Girling, R. (2015), Design Maturity Survey: From Self-Assessment to Action, [online] Artefact Group. Available at: https://www.artefactgroup.com/articles/design-maturity-survey/ (accessed 1.9.2018).

Gruber, M., de Leon, N., George, G. and Thompson, P. (2015), "Managing by Design", Academy of Management Journal, Vol. 58 No. 1, pp. 1-7. https://doi.org/10.5465/amj.2015.4001.

Hassi, L. and Laakso, M. (2011), "Conceptions of design thinking in the design and management discourses", 9th European Academy of Design Conference.

Kolko, J. (2015), "Design Thinking Comes of Age", Harvard Business Review, Vol. 2015, pp. 66-71.

Liedtka, J. (2011), "Learning to use design thinking tools for successful innovation", Strategy \& Leadership, Vol. 39 No. 5, pp. 13-19. https://doi.org/10.1108/10878571111161480.

Liedtka, J., Salzman, R. and Azer, D. (2017), "Democratizing Innovation in Organizations: Teaching Design Thinking to Non-Designers", Design Management Review, Vol. 28, https://doi.org/10.1111/drev.12090.

Mozota, B.B. (2010), “The Four Powers of Design: A Value Model in Design Management", Design Management Review, Vol. 17 No. 2, pp. 44-53. https://doi.org/10.1111/j.1948-7169.2006.tb00038.x.

Rae, J. (2016), "Design value index exemplars outperform the S\&P 500 index (again) and a new crop of design leaders emerge", Design Management Review, https://doi.org/10.1111/drev.12040.

Rauth, I., Carlgren, L. and Elmquist, M. (2014), "Making It Happen: Legitimizing Design Thinking in Large Organizations", Design Management Journal, Vol. 9 No. 1, pp. 47-60. https://doi.org/10.1111/dmj.12015.

Walters, H. (2011), Design Thinking' Isn't a Miracle Cure, but Here's How It Helps, [online] Fast Company. Available at: https://www.fastcompany.com/90186356/design-thinking-isnt-a-miracle-cure-but-heres-howit-helps (accessed 1.9.2018).

Westcott, M., Sato, S., Mrazek, D., Wallace, R., Vanka, S., Bilson, C. and Hardin, D. (2013), “The DMI Design Value Scorecard: A New Design Measurement and Management Model”, Design Management Review, Vol. 24 No. 4, pp. 10-16. https://doi.org/10.1111/drev.10257.

\section{ACKNOWLEDGMENTS}

This research would not have been possible without Design+, a research project funded by the Finnish Work Environment Fund (grant 117110), Aalto University, and participating companies. We are thankful for the funding, support of the larger research team, as well the time of the interviewees. 